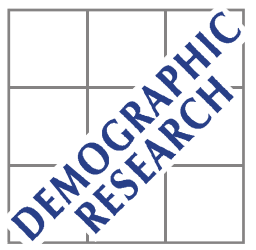

Demographic Research a free, expedited, online journal of peer-reviewed research and commentary in the population sciences published by the Max Planck Institute for Demographic Research Konrad-Zuse Str. 1, D-18057 Rostock · GERMANY www.demographic-research.org

DEMOGRAPHIC RESEARCH

VOLUME 26, ARTICLE 4, PAGES 99-130

PUBLISHED 14 FEBRUARY 2012

http://www.demographic-research.org/Volumes/Vol26/4/

DOI: 10.4054/DemRes.2012.26.4

Research Article

The fertility of immigrants after arrival:

The Italian case

Eleonora Mussino

Salvatore Strozza

(C) 2012 Eleonora Mussino \& Salvatore Strozza.

This open-access work is published under the terms of the Creative Commons Attribution NonCommercial License 2.0 Germany, which permits use, reproduction \& distribution in any medium for non-commercial purposes, provided the original author(s) and source are given credit. See http:// creativecommons.org/licenses/by-nc/2.0/de/ 


\section{Table of Contents}

$1 \quad$ Introduction 100

$2 \quad$ Empirical evidence on fertility from aggregate cross-sectional data $\quad 101$

3 From the literature on immigrant fertility to the research hypotheses 104

4 The 2003 cohort of Albanian, Moroccan, and Romanian immigrants 106

$\begin{array}{lll}5 & \text { Method and variables } & 109\end{array}$

6 Which demographic and migratory factors most influence the risk of having a first child for the 2003 cohort of immigrants in Italy? 110

6.1 Descriptive overview 110

6.2 Transition to first birth in Italy 113

6.3 Determinants of first birth in Italy 115

$\begin{array}{llr}7 & \text { Discussion } & 122\end{array}$

$\begin{array}{lll}8 & \text { Acknowledgements } & 123\end{array}$

References 124

Appendix 129 


\title{
The fertility of immigrants after arrival: The Italian case
}

\author{
Eleonora Mussino ${ }^{1}$ \\ Salvatore Strozza ${ }^{2}$
}

\begin{abstract}
BACKGROUND

Previous studies show that migration and fertility may be strongly connected and that the migration history and duration of stay should be included in the analysis of reproductive behavior of foreign women.
\end{abstract}

\section{OBJECTIVE}

This study investigates the risk of having a first child in Italy for Albanian, Moroccan, and Romanian women, currently the three largest groups of immigrants to Italy.

\section{METHODS}

By implementing record linkage procedures, we were able to use a longitudinal approach on Italian cross-sectional administrative data on births and international migration. Following the 2003 cohort of immigrants, we estimated the hazard ratio of having a first birth in Italy in the period 2003-2006 using the piecewise-exponential model.

\section{RESULTS}

Strong differences by citizenship in the fertility pattern remain even when we control for migratory and demographic factors. At the same time, there is a clear pattern in the timing of motherhood for the different types of migration.

\section{CONCLUSIONS}

Different citizenships also have different timings of reproduction when the migratory model is taken into account. The high risk for family reasons in the short period is obviously related to the hypothesis of interrelated events, whereas women who come for work reasons need more time to adjust and to decide to have children in the host country.

\section{COMMENTS}

This study in line with the international literature confirms that, besides the strong arrival effect for the new immigration cohorts on the risk of having a birth in Italy, there is a strong interrelation between the migration and family behavior.

\footnotetext{
1 Corresponding author. Sapienza University of Rome. Italian National Institute of Statistics (ISTAT). E-mail: eleonora.mussino@gmail.com. Tel.: +39 0646734998.

${ }^{2}$ University of Naples Federico II.
} 


\section{Introduction}

In Italy, the decline in the total fertility rate (TFR) in recent decades has been particularly strong, even compared to many other European countries (Delgado Perez and Livi Bacci 1992). It is also well known that fertility in Italy is still low (Goldstein, Sobotka, and Jasilioniene 2009). The slight increase recorded in the last few years is in part attributed to the arrival of growing numbers of foreign women, and the significant increase in the foreign female population of childbearing age raises questions about their fertility patterns. Some studies have focused on the impact made by foreigners on Italian period TFR, concluding that the fertility of foreign women is a central factor in the increase of fertility (Billari 2008). Even if it contributes only in part to the recent increase in total fertility, it has had a more important role in pushing up the TFR in Italy than in other European countries (Goldstein, Sobotka, and Jasilioniene 2009). The international literature highlights a strong impact on period fertility due to the high risk of fertility shortly after migration (Alders 2000), so an increase in the number of immigrants may have a direct influence on the TFR. But different citizenship groups have different propensities (Andersson 2004; Sobotka 2008), so the composition of the immigrant flow has to be taken into account. Furthermore, reproductive strategies are often determined by different migration patterns. One can suppose that this is true at least in terms of time and place of childbearing. These considerations point out the importance of studying the determinants of fertility behavior of foreign women and in particular the relationship between international migration and fertility, especially considering a destination country, such as Italy, that has recorded exceptional immigration over the last decade, and has a large heterogeneity by citizenship of immigrants.

This article presents an analysis of the reproductive behaviors of the 2003 cohort of female immigrants to Italy. An initial picture of the heterogeneity of reproductive behaviors of the major foreign communities present in Italy is derived from macro-data provided by official statistics. This information allows us to hypothesize that the differences in immigrant women's reproductive behavior may depend not only on the different contexts of origin (i.e., country of citizenship) but also on different types of migration (for family reunification or for work). The use of micro-data then allows for in-depth analysis. In particular, owing to the lack of specific longitudinal data, record linkage procedures were implemented in order to consider different cross-sectional administrative sources. We implemented record linkage procedures on Italian administrative data on births and residence permits.

This ad hoc dataset enabled us, for the first time, to follow a cohort of immigrants and study their transition to the first child in Italy. With this unique dataset, we aimed to answer a specific research question: Which are the demographic and migratory factors 
that most influence the risk of having a first child for the 2003 cohort of immigrants in Italy? To answer this question, we focused on the three largest non-Italian citizenship groups: Albanians, Moroccans, and Romanians.

The organization of this paper is as follows: After this introduction, we present (in Section 2) a short overview of the fertility pattern of women in Italy and identify the differences between the main foreign citizenships in the synthetic values of period fertility. The fertility of foreign women is a complex subject that raises important questions on the demographic as well as the political level. Many studies on various aspects of the fertility of international migrants have been reported in the demographic literature; in Section 3, we present the competing hypotheses underlying the one that most inspired our assumptions for this work, and which we could test with the information from our dataset. The construction of the dataset for this study is explained in Section 4, and the method of analysis described in Section 5. Section 6 discusses the results, and Section 7 provides a concluding summary.

\section{Empirical evidence on fertility from aggregate cross-sectional data}

Several European countries in recent decades have seen profound changes in the pattern of major demographic indicators. Low fertility levels as well as reduction in mortality, especially in older age, have been observed. Mediterranean countries, including Italy in particular, have experienced a strong decline in fertility. During the 1950s, the Italian period TFR was more than 2.5 and in 1964 increased to 2.7 children per woman; this baby-boom was followed by a continuous decline that reached a low point of 1.19 children per woman in 1995 . In the last 15 years, there has been a slight recovery: today, the Italian TFR is about 1.42. This recent increase is attributed to two different phenomena: the first is the change of the mean age at childbearing; the second is the contribution provided by the growing foreign resident population.

The postponement of childbearing initially led to the period TFR being lower than the cohort TFR with a recovery in the most recent years (Caltabiano 2006). The last 50 years have witnessed a change in timing of fertility that represents a significant disparity between the TFR of the period and cohort (Rinesi 2009). Today, the mean age at delivery is 31.1 years for the entire resident population, compared to 29.8 in 1995 (ISTAT 2010).

At the same time, there was an increase in the number of births from two foreign parents. In 2008 , the 72,000 foreign births represented $12.6 \%$ of the total births, compared to only $4 \%$ in 1999. If births with only one foreign parent are also considered, the 2008 percentage increases to $16.7 \%$. It is interesting to consider the synthetic measure of period fertility separately by national and foreign women: Italians 
have a TFR of 1.32 with a mean age at childbearing of 31.7 years, while foreigners have 2.31 children with a mean childbearing age of 27.9 years. The mean age at childbearing is calculated without considering parity, so it assumes even more importance if it is realized that foreign women have almost twice the TFR of Italian women. Ferrara et al. (2009) confirm that the variation of period fertility between 2001 and 2006 appears to be due to the increased proportion of foreign presence in Italy and a slight increase in fertility among native women, but also because foreign women contributed to a slowdown in the postponement of fertility. Therefore, without the contribution of foreign women, Italy would still have lowest-low fertility, at least for the estimated values of 2005 and 2007 (Goldstein, Sobotka, and Jasilioniene 2009). ISTAT (2010) attributes $44.6 \%$ of the recent recovery of Italian fertility levels to births of foreign mothers, and the remaining $55.4 \%$ to the recovery of postponed births by the generation of Italian women born between the late 1960s and early 1970s. But while the trend for Italian women is still positive, we observe there is a slow decrease in the TFR of foreign women. This can mainly be attributed to the high heterogeneity in the fertility pattern across citizenships (Sobotka 2008) and the change of the composition of the foreign population in recent years. Recently, more immigrants are coming from lower-fertility countries, especially from eastern and south-eastern Europe. ISTAT investigated the variability across citizenships. If we consider the ten foreign citizenships with the highest number of births in 2005, the TFR ranges from 1.23 for Ukrainian women to 5.53 for Egyptian women (in their home countries, the values are 1.12 and 3.29, respectively). With the exception of Ukrainians, all citizenships have a higher TFR and a lower mean age at childbearing than those of Italian citizens (Table 1). The report also showed that the high variability in fertility is also affected by the existence of an Italian partner (father of the child). Women from low-fertility countries, such as Ukraine and Poland, who also show a low level of fertility in Italy, have a high probability of being in a union with an Italian partner (ISTAT 2007).

Another aspect that must be considered is the role of the woman in the migration process, which varies substantially by citizenship and which can have a significant impact on the intensity and timing of immigrant fertility. With regard to migratory patterns, the range of situations observed is broad in Italy, as in other receiving countries. The two extremes are citizenships in which adult women have almost all immigrated for family reunification (this is the situation especially for North African and Indian sub-continent immigrants) and citizenships in which women have come for work, along with other relatives or alone (common among Eastern European and Latin American immigrants). The 2005 data for each of the top twenty citizenships allow us to see the strong positive correlation (0.83) between the values of the TFR and the 
shares of residence permits ${ }^{3}$ for family reasons (among women in reproductive age). Without doubt, the most traditional countries are often those with higher levels of fertility, and with migration patterns in which the man is frequently the main actor and the architect of the success of the project. Citizenship, however, seems not enough to synthesize both these aspects. The role of women in the migration process, even controlling for citizenship, can be an important factor that could significantly affect the reproductive behavior of immigrants, and this should be considered in theories around this topic.

Table 1: Total fertility rate for the main citizenship groups in Italy and in their home country in $\mathbf{2 0 0 5}$

\begin{tabular}{lccccr}
\hline Country of citizenship & $\begin{array}{c}\text { TFR in } \\
\text { the home } \\
\text { country (a) }\end{array}$ & TFR in Italy & $\begin{array}{c}\text { General } \\
\text { fertility rate } \\
\text { (births per } \\
\mathbf{1 , 0 0 0} \text { women } \\
\text { aged 15-49) }\end{array}$ & $\begin{array}{c}\text { Mean age at } \\
\text { childbearing }\end{array}$ & $\begin{array}{c}\text { \% with } \\
\text { Italian } \\
\text { partner }\end{array}$ \\
\hline Morocco & & & & \\
Albania & 2.76 & 4.19 & 151 & 28.6 & 6.8 \\
Romania & 2.29 & 2.75 & 108 & 26.4 & 9.9 \\
China & 1.32 & 1.98 & 72 & 26.8 & 28.0 \\
Tunisia & 1.70 & 2.92 & 103 & 27.3 & 3.0 \\
Poland & 2.00 & 4.52 & 175 & 29.3 & 5.5 \\
Ukraine & 1.24 & 1.54 & 55 & 28.1 & 69.8 \\
Philippines & 1.12 & 1.23 & 26 & 27.4 & 62.2 \\
Ecuador & 3.22 & 1.81 & 47 & 28.6 & 9.2 \\
Egypt & 2.82 & 2.03 & 64 & 27.4 & 24.1 \\
\hline
\end{tabular}

Note: (a) The value for home country is from the UN (mean value for 2002-2005).

Source: ISTAT 2007.

\footnotetext{
${ }^{3}$ Foreigners who intend to stay in Italy for more than three months must apply for a residence permit. Those arriving in Italy for the first time have eight days to ask for permission to stay, but from 1st January 2007 those who came from countries included in the EU-27 did not need a residence permit. As our data refer to 2003, all adult Romanians were holders of residence permits.
} 


\section{From the literature on immigrant fertility to the research hypotheses}

Several different and sometimes conflicting theories on the fertility patterns of immigrants have been proposed in the past, and it should be kept in mind that the hypotheses presented may not be mutually exclusive (Mussino and Van Raalte 2008; Milewski 2010). First of all, it has been pointed out that the strong heterogeneity of fertility behavior and propensities of childbearing of foreign women may be associated with their various countries of birth, citizenship, or origin (Andersson 2004; Sobotka 2008). Women from different countries come from places with different fertility patterns; they have different migration histories, different levels of integration, and different kinds of family structures. All these factors have an impact on their choice to have children in the host country. Then the influence of citizenship is an indicator of the effect of socialization - how background affects reproductive choices; it summarizes the norms and values of the home country (Stephen and Bean 1992; Kahn 1994; Schoenmaeckers, Lodewijckx, and Gadeyne 1999; Alders 2000). We assumed in our study that the impact of citizenship would remain important even if we controlled for the other demographic characteristics and the migratory models of the women. Specifically, we hypothesized that we would observe different family sizes and different timings of having children, which would reflect behavior in their home countries.

A number of hypotheses on the effect of migration on childbearing are illustrated in the literature. As an alternative to the disruption ${ }^{4}$ hypothesis, which would expect a delay in childbearing right after migration due to the stress of the move (Milewski 2010), we assumed a peak in the risk of childbearing in the short term after arrival (Ng and Nault 1997). Ford (1990) demonstrated the importance of considering the duration of stay and the possibility that the short-term effect had a strong impact on fertility behavior. The strength of this "arrival" effect is higher if there is a strong interrelation between family reunion (formation) and migration (Mulder and Wagner 1993; Singley and Landale 1998). This theory assumes that the demographic events experienced by the individual over the life course are strictly connected (Willekens 1991; Mulder and Wagner 1993). Studies have found dependence among internal or international migration, marital status, and fertility career (Courgeau 1989; Mulder and Wagner 1993), especially when the risk of having a first birth is considered (Milewski 2007).

\footnotetext{
${ }^{4}$ This hypothesis assumes that migration causes a drop in fertility in the immediate periods before, during, and after migration (Mayer and Riphahn 2000). Some studies found a "catch-up" by a subsequent acceleration of fertility to compensate for earlier delays (Goldstein and Goldstein 1981; Ford 1990; Kahn 1994) while others found that spouse separation, economic insecurity, and stressful situations may contribute to the postponement of childbearing and consequently lower fertility (Hervitz 1985; Brockerhoff 1995).
} 
When migration is associated with family reasons, we expect an elevated risk of childbearing. Adult women, who move to join their partner in the receiving country, if they have not had children previously, often concentrate their reproductive period in the years immediately following their migratory event. In contrast, women who migrate for employment reasons, especially if they became breadwinners and/or have to prepare a situation for the later arrival of family members may postpone the birth of their children even some years after the migratory event.

In studying the 2003 cohort of non-Italian immigrants with respect to the risk of having the first child in a short period, we could not compare different cohorts; we assumed, therefore, that adaptive behavior would not be shown, where by "adaptive" we mean a slow convergence in fertility behavior related to the duration of the exposure to the host society (Kahn 1988; Ford 1990). For example, Schoorl (1990) in a study of immigrant women on Turkish and Moroccan descent in the Netherlands, justifies the reduction of fertility after migration with an adaptation process over time. As this cohort would not have time to adapt behavior, the risk could mainly depend on the reason for migration and could show an arrival effect.

While in this study we focused on the disruption, socialization, life course, and some aspects of the adaptation hypotheses, we had to consider that two other important theories arise from the literature: selectivity and minority status. The first theory (selectivity) considers that immigrants may already have fertility intentions similar to those of the receiving country and different from those of their country of origin. This selection can be affected by "observed" characteristics, such as education (Wagner 1990; Blau 1992), or by "unobserved" factors, ${ }^{5}$ such as social mobility ambition or family orientation. Unfortunately, our data do not include the socio-economic information and the characteristics of the individual before the migration; in particular, we do not have information for the "not-migrating" population so we cannot test this hypothesis. The second theory (minority status) takes mainly into account descendants and groups with a strong identity ${ }^{6}$ or other groups discriminated against by members of the majority group (Sly 1970; Kennedy 1973; Bean and Wood 1974; Ritchey 1975; Bean and Tienda 1990). In the Italian context, however, we assume that is still too early to test this approach.

Starting from these theories, we focused on the 2003 cohort of Albanian, Moroccan, and Romanian immigrants and hypothesized that Moroccan women have a high fertility level in the host country, especially shortly after migration (Coleman 1994; Alders 2000). We expected that the difference would be stronger if compared to women from Romania, not only because the proportion of women who come to Italy

\footnotetext{
${ }^{5}$ Ribe and Schultz (1980) argue that migrants have a clear "unobserved" preference for family size and that their fertility propensity is one of the factors that determine the place of destination.

${ }^{6}$ That is, groups with social or religious cohesion, sub-national, ethnic, or physical resemblance.
} 
for family reasons is higher for Moroccans than for Romanians, but mainly because the fertility pattern in the home country is different. However, we assumed that marital status would influence the reproductive behavior, meaning that married women would have a higher risk of bearing a child than the non-married. Even the effect of marital status might differ by citizenship; previous studies have shown that a high proportion of Moroccan women are single when they migrate and marry soon after migration (Schoorl 1990; Alders 2000). Furthermore, we assumed that a large proportion of Moroccan women would move for family reunion so as to have a child shortly after migration. Duration was not expected to have the same effect for Romanians, who come to Italy mainly for work reasons. We hypothesized that the deadline for legal presence would influence future plans and security of the stay in Italy. We assumed that reproductive choices would be positively associated with an indeterminate residence permit in the host country.

\section{The 2003 cohort of Albanian, Moroccan, and Romanian immigrants}

The aim of this research is to study the reproductive behavior of foreign women in Italy. Previous studies show that migration and fertility may be strongly connected and that the migration history and duration of stay should be included in an analysis of reproductive behavior of foreign women (Toulemon and Mazuy 2004; Milewski 2010). The official sources available today in Italy do not enable us to study more than one of these two demographic behaviors simultaneously (fertility and migratory career), especially as part of a longitudinal approach. To overcome these limitations in the data and to give proper importance to the information from administrative sources, we implemented record linkage procedures. We applied a record linkage procedure between the Reproductive History Dataset (RHD) and residence permits.

The first source (RHD) was identified using a first record linkage (RL) with the annual Survey on Live Births ${ }^{7}$ in the period 2003-2006. It includes 283,700 births from 252,330 foreign and foreign-origin mothers. This dataset was built with deterministic $\mathrm{RL}$ procedures described in detail in a previous article (Mussino et al. 2009). It reconstructs the fertility history of foreign mothers in the short period considered, so that we can use the results of the record linkage as panel data. The new information

\footnotetext{
${ }^{7}$ The continuous current data collection on live births in Italy is collected by Municipal Population Registers and recoded by ISTAT with the so-called "Survey on Live Births," a total survey that has collected since 1999 all events recorded in Municipal Population Registers. The individual form (P4) includes information on births (date and place of birth, citizenship), parents (date of birth, citizenship, and marital status) and the main details of the head of the household.
} 
received from the record linkage enabled a study of the timing of one or several births. To sum up, the aim of the record linkage was to create a dataset of foreign mothers on the basis of events obtained from a dataset on births. In this way, each mother was linked to all her births during the period 2003-2006. ${ }^{8}$

The second source consists of the data on residence permits, which represents the main source on the legal presence of foreigners in Italy. ${ }^{9}$ This register includes information on the demographic (sex, age, marital status, citizenship) and on the migration characteristics (date of arrival, duration, and reason for permit) of foreigners holding a permit. For these data, the information is collected by province because this is the smallest administrative aggregation for police headquarters.

While in the RHD we have information on the first and last name of each individual, in the residence permit data, these variables are joined in one, and unfortunately vowels ${ }^{10}$ are deleted. Therefore the data lack unique identifiers and distinguishing variables, so that we had to apply a probabilistic record linkage by performing the EM algorithm (Fellegi and Sunter 1969) for the estimation of the parameters. The key variables that we used were then the union of the mother's name and surname without vowels, date of birth, and citizenship. As part of the procedure, we added information on fertility for a recently immigrated cohort of foreign women. We linked residence permits at the end of 2003, granted to all women who arrived in Italy in 2003, with the RHD, adding information on fertility for the recently migrated cohort of foreign women. Thus, the populations were not expected to be exactly the same: not all women had a child in Italy.

Specifically in this second RL, we followed 25,402 women from Albania, Romania, and Morocco recorded for the first time in 2003 in Italy, of whom 6,436 women gave birth to their first child in the host country in the following years. Figure 1 gives the corresponding Lexis diagram, in which calendar time for the years 2003-2006 is plotted on the horizontal axis and duration in years since immigration on the vertical axis. The figure shows the cohort of the three foreign citizenships who arrived in Italy in 2003 and the number of first births recorded in the following three years.

\footnotetext{
${ }^{8}$ The reason we have 283,700 births from 252,330 mothers is that a mother is counted only once and not every time that she is registered at the time of giving birth.

${ }^{9}$ The Ministry of the Interior records the data on all residence permits, and ISTAT processes and releases the set of data, since 1992, at the beginning of each year.

${ }^{10}$ In the Italian language, vowels are the letters $a, e, i, o$, and $u$.
} 
Figure 1: Lexis diagram for births from 2003 cohort of immigrant women

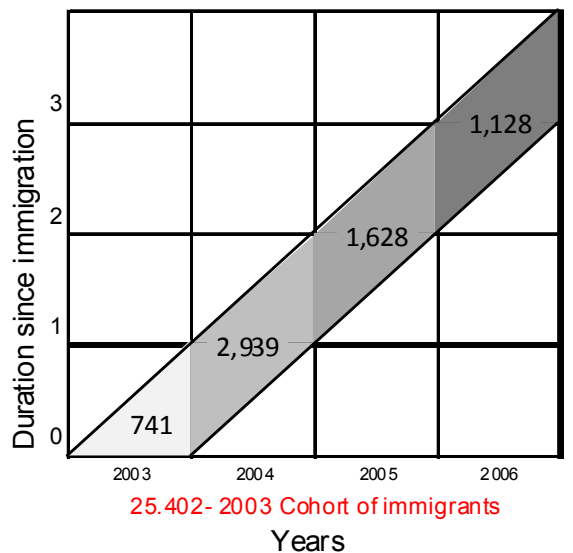

Table 2 shows the number of women considered and the number of first children born in Italy during the period, categorized by the three citizenships. For these links, the estimated probability a posteriori of being the same individual in the two data sources was $0.99 .^{11}$

Table 2: Link between cohort of immigrants who arrived in Italy in 2003 and fertility information

\begin{tabular}{lrrrr}
\hline & Albanian & Romanian & Moroccan & \multicolumn{1}{c}{ Total } \\
\hline Women arrived 2003 & 8,087 & 11,442 & 5,873 & 25,402 \\
Births in period from January 1st, 2003 to & 2,632 & 1,200 & 2,604 & 6,436 \\
$\quad$ January 1st, 2007 & & & & \\
\hline
\end{tabular}

Due to the high mobility of the foreign population (De Santis 2010; de Filippo and Strozza 2011), we decided to conduct a third record linkage. In this third step, we included only women known to have stayed in Italy until the end of the observation period. The probabilistic approach for this step is much weaker compared with the previous one because, from 2005, the first and last names were no longer recorded in the residence permit register. We decided, therefore, to attempt a deterministic linkage. Of the 25,402 women who arrived in Italy during the year 2003, 16,655 appear to be

11 The distance between the distribution of the comparison vectors in the set of matches $(\mathrm{m})$ and the corresponding distribution in the set of non-matches (u) is large, and the area where they overlap is small. This indicates that a high quality of results is achieved. 
still in the host country at the beginning of 2007. This third dataset is only used to verify the robustness of the results of our analysis. The fact that the residuals of this RL appear random suggests that the procedure may be trusted; nevertheless, we only use this data set as a robustness check for our analysis because of the weakness of the key used for the RL.

We could not test the selectivity of our population with respect to others in the country of origin. We could, however, by using register data, avoid problems of sample selection related to other migrants in Italy, that may be missing in survey data sources because of language proficiency or territorial mobility. We could also solve the data problem by constructing an ad hoc dataset that allows a longitudinal approach and combines fertility and migration information. With the last RL, even if the results were used only as a robustness check, we could try to evaluate the importance of the problem of emigration bias.

\section{Method and variables}

Using the data on the 2003 cohort of immigrants, we estimated the hazard ratio of having a first birth in Italy using the piecewise-exponential model (Allison 1984; Blossfeld and Rohwer 2002). For the process of having a first birth, the entry in the process was the arrival time in Italy, and the hazard was assumed to be constant within each of the segments $(0-12,12-18,18-24,24-36$ months and 36 months and over), but the hazard might vary between segments. We started by considering all women in the sample. We then included, in the second model, only women aged 20 years or younger because we assumed that for them the first birth in Italy is also the first child in general. ${ }^{12}$ Women who did not have a child during the observation window were rightcensored at the end of 2006. It was not possible to censor those who left Italy or died during the observation at the exact time when the event happened. Therefore, we decided to run a third model just for women for whom it was possible to check whether they were still living in Italy at the beginning of 2007. This last model has to be considered just as a robustness check, because the assumptions made for the record linkage procedure were too weak (see the end of Section 4).

The available independent variables do not cover all aspects, but enable us to contribute to the international debate. Diverse fertility behavior can be associated with cultural differences among the countries of origin (Andersson 2004). As an indicator of this cultural effect, we inserted the variable citizenship of the women into the models, assuming it to be the most important factor in explaining the heterogeneity between the

\footnotetext{
${ }^{12}$ This hypothesis is confirmed by the data: $80 \%$ of the women in this age group who have a child in this period do not live with minors.
} 
groups. Toulemon (2004) shows that the age at arrival can have different impact on the reproductive behaviors. This variable was categorized into five age groups $(<20,20-24$, $25-29,30-34,35$ and older). Another aspect of the duration of stay was considered by including in the analysis the deadline for the residence permit: we categorized this as "determinate" if any date was specified, otherwise "indeterminate." We also considered the place of arrival, as previous Italian studies had shown that immigrants have different patterns and behaviors in the various geographical areas of Italy (Terzera 2006; Blangiardo 2009). Italian territory was divided into the geographical divisions of NorthEast, North-West, Central, and South and Islands. Milewski (2010) assumes that, for the first immigrant generation, marriage before migration influences fertility after the move. Accordingly, marital status at arrival is also included in the analysis ("married" vs. "other").

Different motivations for migration can have different impacts on reproductive behavior. Generally, this is studied as the interrelation between processes (Courgeau and Lelievre 2006). In this case, we had information on the reason for residence permit, which helped to understand, at least formally, the individual's choice of migration. The reasons were categorized in, a first step, as "work," "family," "health,", and "other." In a second step, women who had a residence permit for health reasons were eliminated from the analysis (see Section 6.3 for reasons) and the variable was divided into only three modalities. The distinction between labor and family reunion migration could be an important element in understanding the reproductive behavior of female immigrants, also when other aspects are considered in the analysis.

\section{Which demographic and migratory factors most influence the risk of having a first child for the 2003 cohort of immigrants in Italy?}

\subsection{Descriptive overview}

The study focused on 25,402 women from the three largest citizenship groups, Albanian, Moroccan, and Romanian, which arrived in Italy in 2003. Table 3 shows the main demographic and migratory characteristics at arrival for each of the three citizenships.

Albanians were the youngest of all three groups of women who arrived in Italy in 2003; nearly $55 \%$ of them were less than 25 years old. This proportion was considerably smaller for Romanians (38\%) and Moroccans (45\%). Likewise, the

\footnotetext{
${ }^{13}$ Illegal or irregular pregnant immigrant women may obtain a health residence permit until the sixth month after the birth of the child (Spinelli 2005).
} 
distribution by reason for residence permit appears to be heterogeneous. Moroccans came to Italy almost exclusively for family reasons (90.9\%) and only $7 \%$ for work reasons. To come to Italy for family reasons was also very common for Albanians (78\%) but considerably less often the case for Romanians (33.4\%). Romanians were more likely to receive a residence permit for work reasons $(28 \%)$ or tourism reasons (almost $27 \%$ ). ${ }^{14}$ About $12 \%$ of Albanian women, however, came to Italy for study purposes. This might explain the higher percentage of Albanian women who were under 20 years old. These dissimilarities among citizenships also explain the large differences by expiration date of the residence permits. In only $0.75 \%$ of cases did Romanians have an indeterminate residence permit, while this percentage was more than $10 \%$ for Moroccans. The north-west regions were the destinations of more migrants than any other geographical division. The pattern was more evident for Moroccan women. Most Moroccans came to Italy for family reunification. This is explained by the high percentage of married women but is also linked to family formation reasons. Therefore the percentage of permits for family reasons is higher than the percentage of married women. Romanians, however, were not married in more than $51 \%$ of cases. As previously seen, Albanians show an intermediate pattern: $76 \%$ of them were married when they came to Italy.

${ }^{14}$ In order to enter the country, the foreigner must have a valid passport upon crossing the border. This kind of permit does not allow the holder to work. Since 2007, this kind of permit is required only for periods longer than three months, but for the period of observation in this study it was mandatory also for short stays. 
Table 3: $\quad$ Percentage distribution of 2003 cohort of immigrant women by age at arrival, characteristics of the residence permit, Italian geographical area of presence, and marital status, by citizenship

\begin{tabular}{|c|c|c|c|c|}
\hline & Albanian & Romanian & Moroccan & Total \\
\hline \multicolumn{5}{|l|}{ Age at arrival } \\
\hline$<20$ & 30.38 & 12.27 & 19.29 & 19.66 \\
\hline $20-24$ & 24.19 & 26.11 & 25.87 & 25.44 \\
\hline $25-29$ & 14.00 & 24.51 & 20.91 & 20.33 \\
\hline $30-34$ & 9.69 & 15.65 & 14.06 & 13.39 \\
\hline 35 and older & 21.74 & 21.46 & 19.87 & 21.18 \\
\hline Total (\%) & 100.00 & 100.00 & 100.00 & 100.00 \\
\hline \multicolumn{5}{|l|}{ Reason for permit } \\
\hline Work & 5.80 & 27.98 & 6.69 & 15.99 \\
\hline Family & 78.03 & 33.44 & 90.92 & 60.92 \\
\hline Study & 11.88 & 2.80 & 0.89 & 5.25 \\
\hline Tourism & 0.79 & 26.80 & 0.20 & 12.37 \\
\hline Health & 2.82 & 6.44 & 0.94 & 4.02 \\
\hline Other & 0.68 & 2.54 & 0.36 & 1.45 \\
\hline Total (\%) & 100.00 & 100.00 & 100.00 & 100.00 \\
\hline \multicolumn{5}{|l|}{ Deadline of permit } \\
\hline Determinate & 97.84 & 99.25 & 89.82 & 96.62 \\
\hline Indeterminate & 2.16 & 0.75 & 10.18 & 3.38 \\
\hline Total (\%) & 100.00 & 100.00 & 100.00 & 100.00 \\
\hline \multicolumn{5}{|c|}{ Italian geographical division } \\
\hline North-West & 32.82 & 30.89 & 40.49 & 33.71 \\
\hline North-East & 28.30 & 29.72 & 32.42 & 29.90 \\
\hline Central & 27.15 & 27.57 & 13.64 & 24.22 \\
\hline South \& Islands & 11.73 & 11.82 & 13.45 & 12.17 \\
\hline Total (\%) & 100.00 & 100.00 & 100.00 & 100.00 \\
\hline \multicolumn{5}{|l|}{ Marital status } \\
\hline Other & 23.85 & 51.04 & 17.71 & 34.68 \\
\hline Married & 76.15 & 48.96 & 82.29 & 65.32 \\
\hline Total $(\%)$ & 100.00 & 100.00 & 100.00 & 100.00 \\
\hline Absolute values & 8,087 & 11,442 & 5,873 & 25,402 \\
\hline
\end{tabular}

Source: Record linkage from 2003 cohort of immigrants and RHD (authors' calculations).

A total of 6,436 of the 2003 cohort of immigrants from Albania, Morocco, and Romania could be linked with the RHD, which means that they gave birth to at least one child in Italy in the period 2003-2006 (25.3\% of all). For these women, who gave birth to at least one child in the period 2003-2006, we have information on partner 
characteristics and parity. Both sets of information are stored only in the RHD and not in the residence permit registers, which is why we do not have these data for the entire population. Table 4 shows that the recorded child (the first child born in Italy) is mainly parity one, ${ }^{15}$ but especially for Moroccans there is a high proportion of women who arrived in Italy with at least one other child. The table shows also that $38 \%$ of Romanians had a child with an Italian partner, while for the other two citizenships this percentage is only about $4 \%$.

Table 4: Percentage distribution of mothers by citizenship of partners and parity, by citizenship

\begin{tabular}{lrrrr}
\hline & Albanian & Romanian & Moroccan & Total \\
\hline Parity & & & & \\
1 & 69.64 & 78.25 & 61.48 & 67.95 \\
2 & 18.58 & 16.92 & 20.47 & 19.03 \\
3 and more & 9.12 & 3.08 & 15.55 & 10.60 \\
Missing & 2.66 & 1.75 & 2.50 & 2.42 \\
Total (\%) & 100.00 & 100.00 & 100.00 & 100.00 \\
Citizenship of the partner & & & & \\
Italian & 4.64 & 37.92 & 3.34 & 10.32 \\
Foreigner & 94.98 & 61.25 & 96.39 & 89.27 \\
Missing & 0.38 & 0.83 & 0.27 & 0.41 \\
Total (\%) & 100.00 & 100.00 & 100.00 & 100.00 \\
\hline Absolute values & 2,632 & 1,200 & 2,604 & 6,436 \\
\hline
\end{tabular}

Source: Record linkage from 2003 cohort of immigrants and RHD (authors' calculations).

\subsection{Transition to first birth in Italy}

In this section, we report on the transition to first birth in Italy for the 2003 cohort of immigrants. The Kaplan-Maier curves presented here give an estimate of the proportion of women and the timing of becoming mothers. We include only women who came to Italy during their fertile period, which means that only women aged 14 to 50 years were considered in the analysis: 24,933 women, more than $98 \%$ of the total were in their fertile period. The "process time" is duration since arrival in the host country. Figure $2 \mathrm{a}$ illustrates the transition to first birth in Italy by citizenship of the woman. The differences among the three survival curves are statistically significant. The curves

\footnotetext{
${ }^{15}$ The parity information is based on the number of cohabiting children, so is a proxy. We do not have information about any previous child who did not follow the mother to Italy.
} 
show that Moroccans have a higher risk of first delivery in a shorter time than Albanians and Romanians. About $46 \%$ of female immigrants from Morocco had at least one child in the period 2003-2006. This proportion was much lower for Albanians (34\%) and especially for Romanians (12\%). For both Moroccans and Albanians, the arrival effect is elevated. Even one year after arrival, almost $20 \%$ of the first and $12 \%$ of the second group gave birth in Italy.

Figure $2 \mathrm{~b}$ shows the transition to first birth in Italy by age at arrival. Women who migrated at a younger age experienced a greater risk of having a child in the short period after migration, especially between ages 20 and 24 . This result shows that there is no difference between women aged 25-29 years on arrival and women aged less than 20 years on arrival. The proportion of women who did not have a child in Italy is very high for women who came at age 35 or later. More than $95 \%$ of these women did not have a child in the host country in the (approximately) three years following their arrival.

Considered next are the different curves by reason for residence permit (Figure 2c). We can hypothesize that a proportion of the women who came to Italy for health reasons were already pregnant. Therefore, it may be that their migration was really a consequence of their fertility; this would explain the greater risk of first birth in the host country in the very short term. However, the health reason does not for all of them coincide with the pregnancy, so the final proportion of women who did not have children in the short period following their arrival was higher than for women who came for family reasons. No difference was found between work and other reasons. Both groups had the highest levels of women childless in the host country, while there were great differences between women who came for family or work reasons. Of those who came for family reasons, about $40 \%$ had at least one child in the short period after migration. Figure $2 \mathrm{~d}$ also shows that about $66 \%$ of immigrants who had a long-term residence permit became mothers before the beginning of 2007 , while only $25 \%$ of those with determinate permit had a birth in Italy in the short period. 
Figure 2: Transition to first birth in Italy by demographic and migratory characteristics

\section{a) By citizenship}

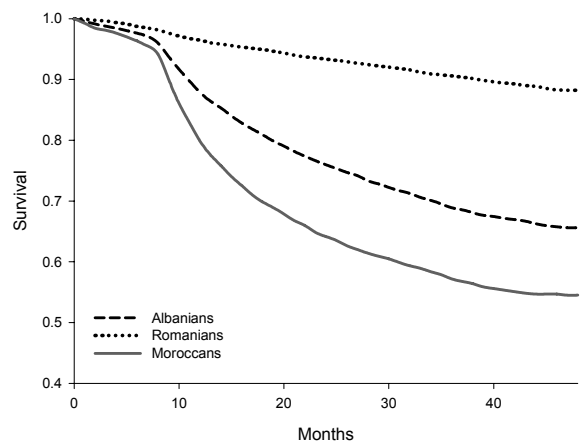

c) By reason for residence permit

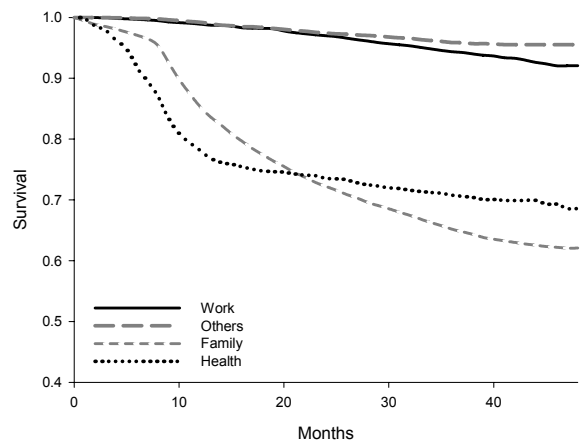

b) By age at arrival

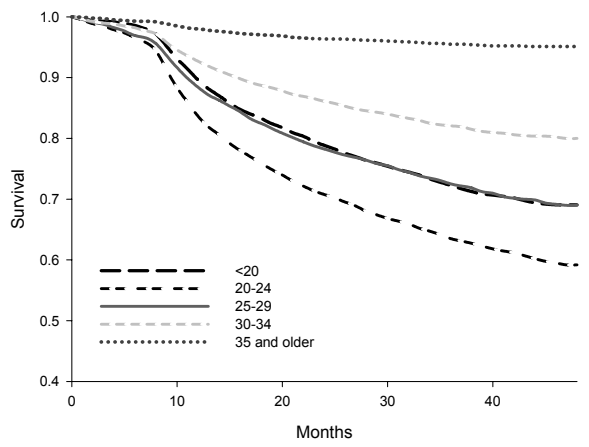

d) By deadline of residence permit

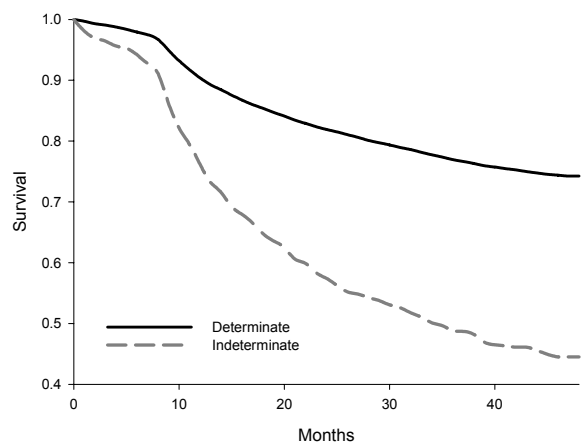

Source: Record linkage from 2003 cohort of immigrants and RHD (authors' calculations).

\subsection{Determinants of first birth in Italy}

By using a multivariate analysis, we wanted to investigate the propensity to have a first birth in Italy. In studying the transition to first childbirth, we concluded that in the case of health reasons there was the possibility that these women could be already pregnant, but we had to consider also that the highest risk for women with a residence permit for health reasons might be linked to the difficulty of maintaining legal residence status. In 
fact, while it is true that women can request a residence permit for health reasons in order to deliver in the same country in which their husband is living, it is also true that this is often used as an "emergency" permit for women who lose their legal status but are already in the process of family formation in Italy. Some international literature refers to this as the legitimacy hypothesis (Bledsoe 2004; Bledsoe, Houle, and Sow 2007; Fleischer 2008). The hazard function of giving birth for these women is not proportional to the hazard function of giving birth for women who migrated for other reasons, violating one of the key assumptions of the piecewise-constant exponential model. This is shown in Figure 2c, where the survival curve for women who migrated for health reasons crosses that of women who migrated for family reasons. For all these reasons, in applying the multivariate model, we did not consider the women came for health reasons, and instead focused our attention on 23,923 immigrants. ${ }^{16}$

The baseline of this model is duration of stay. By studying the transition to the first child, it is easier to test the disruption hypothesis. The idea behind this hypothesis is that the timing of first birth can be postponed when women experience the difficulties of migration. For this reason, duration since arrival is analyzed in small intervals. In this case, the variables were inserted in the model stepwise in order to test the importance: we included first only citizenship, then the reason for migration, and thereafter the control variables. Only the final model is presented here because the introduction of the demographic characteristics of the mother did not change the intensity and the significance of the citizenship of the woman or the reason for her permit. However, to test the different impact of the covariates citizenship and reason for residence permit we decided, starting from the final model, to consider first one and then the other to see which model best explains the variability and so which of the two variables, controlling for the others factors, was more important. Citizenship proved to be the most discriminatory variable. ${ }^{17}$

The results are presented in Table 5. All women of reproductive age on arrival were taken into account in Model $1 .^{18}$ The duration of stay (baseline) did not confirm an initial drop or disruption after the migration, although the risk of having a first child is higher shortly after migration and decreases significantly after 18 months. When the catch-up after the migration is as short as 3-6 months, it often is associated with the interrelation hypothesis (Singley and Landale 1998; Andersson 2004; Lindstrom and Giorguli Saucedo 2007). From this model, it appears that Romanians have a very low risk of having a first child in Italy compared to Albanians. Moroccans, however, have a

\footnotetext{
${ }^{16}$ We applied the selection only in this last step of the analysis because the results of the non-parametric elaboration justified our choice, but we decided to re-run the KM curves, and the results did not change (so are not shown).

${ }^{17}$ In fact, the model without citizenship has a log-likelihood equal to -15861.3 ; the model without reason for permit has a value of -15599.3 .

${ }^{18}$ For distribution of time at risk, see Table A1 in the appendix.
} 
higher hazard ratio with respect to first birth in such a short time period. The variable reason for permit confirms that for the first child there is a strong interrelation between migration and family formation: the fertility risk for women who came to Italy for family reasons is two times higher than for women who came for work reasons. The hazard is higher for married women, thereby clarifying the links between family union/reunion, fertility, and migration. The possibility of staying for a long period is associated with a greater propensity to deliver in the short term. Women with an indeterminate residence permit have a better opportunity to plan their future in Italy, which also encourages maternity. The analysis also included categories for the different geographical divisions of presence in Italy. Women who arrived in Central Italy and in the South and Islands regions have a lower risk of first birth compared to women who arrived in the North. There is no statistical difference between the North-West and North-East. Model 1 also considers the age at arrival. Again, arriving at later ages is clearly linked with a lower propensity to have the first birth in the host country. Probably, older women have already had one or more children in their home country, but unfortunately it is not possible to control for parity at the time of arrival.

For this reason, in the next model (Model 2), we decided to focus only on the women who arrived in Italy before age 21 . For these young women, we assume that their first birth in Italy is probably also their actual first child. Also, for these women, the risk of having a child in the host country is mainly associated with three factors: duration of stay, citizenship, and marital status. 
Table 5: Hazard ratio of having a birth after arrival in Italy for the 2003 cohort of immigrant women

\begin{tabular}{|c|c|c|}
\hline & $\begin{array}{c}\text { Model } 1 \\
\text { All women }\end{array}$ & $\begin{array}{c}\text { Model } 2 \\
\text { Women aged less than } 21 \text { years }\end{array}$ \\
\hline \multicolumn{3}{|l|}{ Duration: } \\
\hline$<=12$ & 1 & 1 \\
\hline $12-18$ & $1.44^{* * *}$ & $1.73^{* * *}$ \\
\hline $18-24$ & $1.15^{\star \star *}$ & $1.46^{\star \star \star}$ \\
\hline $24-36$ & $0.94^{*}$ & $1.33^{* \star *}$ \\
\hline$>36$ & $0.62^{\star * *}$ & 0.94 \\
\hline \multicolumn{3}{|l|}{ Citizenship: } \\
\hline Romanian & $0.45^{* * *}$ & $0.43^{* * *}$ \\
\hline Albanian & 1 & 1 \\
\hline Moroccan & $1.31^{* * *}$ & $1.19^{* *}$ \\
\hline \multicolumn{3}{|c|}{ Reason for residence permit: } \\
\hline Work & 1 & 1 \\
\hline Other & $0.68^{* * *}$ & $0.38^{* * *}$ \\
\hline Family & $1.98^{* * *}$ & 0.97 \\
\hline \multicolumn{3}{|l|}{ Age at first entry: } \\
\hline$<20$ & 1 & \\
\hline $20-24$ & $1.10^{* *}$ & \\
\hline $25-29$ & $0.78^{* * *}$ & \\
\hline $30-34$ & $0.42^{* \star *}$ & \\
\hline 35 and older & $0.09^{* * *}$ & \\
\hline \multicolumn{3}{|c|}{ Deadline of permit: } \\
\hline Determinate & 1 & 1 \\
\hline Indeterminate & $1.24^{* * *}$ & 1.14 \\
\hline \multicolumn{3}{|l|}{ Marital status: } \\
\hline Other & 1 & 1 \\
\hline Married & $3.98^{* * *}$ & $9.87^{* \star *}$ \\
\hline \multicolumn{3}{|c|}{ Italian geographical division: } \\
\hline North-West & 1 & 1 \\
\hline North-East & 0.95 & 1.05 \\
\hline Central & $0.90^{* *}$ & 0.93 \\
\hline South \& Islands & $0.83^{* * *}$ & 0.89 \\
\hline$\overline{\mathrm{LL}}$ & -15468.23 & -3179.10 \\
\hline $\mathrm{BIC}$ & 31144.32 & 6497.24 \\
\hline AIC & 30972.45 & 6386.21 \\
\hline
\end{tabular}

$+<0.1^{*}<0.05^{* *}<0.01^{* * *}<0.001$

Source: Record linkage from 2003 cohort of immigrants and RHD (authors' calculations). 
Again, for the 2003 young cohort of immigrants, a greater risk is observed in the short period. Considering that the observation period starts from the arrival in Italy, and that we cannot control what happened before the migration, as well as the fact that the peak occurs after so short a time, we believe that the disruption hypothesis is not supported in this case but that we can identify an arrival effect. After migration, however, the decrease is significantly slower than in the previous model. The differences by citizenship are strong also for this special subpopulation, although Moroccans only have a $19 \%$ higher propensity than Albanians as compared to the $31 \%$ in the model for all women of reproductive age. Marital status appears to be the most important factor. This confirms the interrelation between first marriage (assumed to be due to the young age) and first child (Baizan, Aassve, and Billari 2003). The hazard ratio is also negatively correlated for women who came to Italy for other reasons.

The observation period, as already mentioned, was rather short. It was assumed that women who decided to have a child in Italy and who recorded that child in the municipal population register would stay in the host country at least for this short interval of years (2003-2006) (Mussino et al. 2009). This assumption would probably be too strong when the whole cohort of foreign women and not just mothers were taken into account. Therefore we planned a final model on women who were assumed to stay until 1 January 2007 in order to see how the results of the initial analysis might be affected by unobserved return migration. The result of this third RL, as mentioned in Section 4, was rather weak. Thus, we decided not to discuss it here but merely use it as a robustness check. Both the random distribution of the residuals of the RL and the results of the model (not shown) indicated that unobserved return migration did not primarily affect our results.

The results of the models, especially Model 1, indicate that citizenship of the women, duration of stay, and reason for residence permit are the main factors that explain the propensity to have a first child in the host country a short time after arrival. Next, we wanted to test whether the possible combination of these three variables, and so of different migratory patterns, have different effects. We assume that the impact of duration of stay is not the same if different citizenships or different reasons for the residence permit are considered.

The results of the interaction between duration since migration and citizenship are shown in Figure 3 (the other covariates are shown in Appendix Table A2, Model 3a and $3 b)$. It seems that there is no duration effect for Romanians, while the likelihood of having a child for Moroccans and Albanians peaks between 12 and 18 months after arrival and decreases thereafter. After 24 months, they both have the same trend. We assumed that a large proportion of Moroccan women would move for family reunion and thus would have a child shortly after migration. Duration was not expected to have the same effect for Romanians, who come to Italy mainly for work reasons. But the 
results are controlled by reason for residence permit, so we assume that is the result of the socialization effect.

Figure 3: Combination of hazard ratio of having a birth after arrival in Italy relative to duration and citizenship (Model 3a)

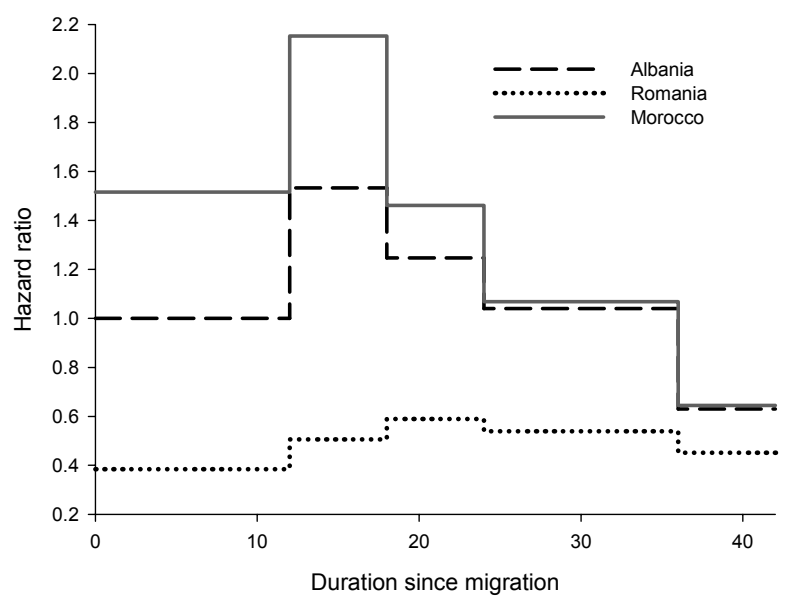

Source: Record linkage from 2003 cohort of immigrants and RHD (authors' calculations).

It is interesting to see (Figure 4) that, for women who came for family reasons, the risk is higher in the short period and then decreases, while for those who came for work reasons, the risk increases with the length of time spent in Italy, as we hypothesized. Furthermore, we also notice that the range of the hazard ratio is higher than in the previous combination, representing the highest risk in the short period for women who came for family reasons. 
Figure 4: Combination of hazard ratio of having a birth after arrival in Italy relative to duration and reason for residence permit (Model 3b)

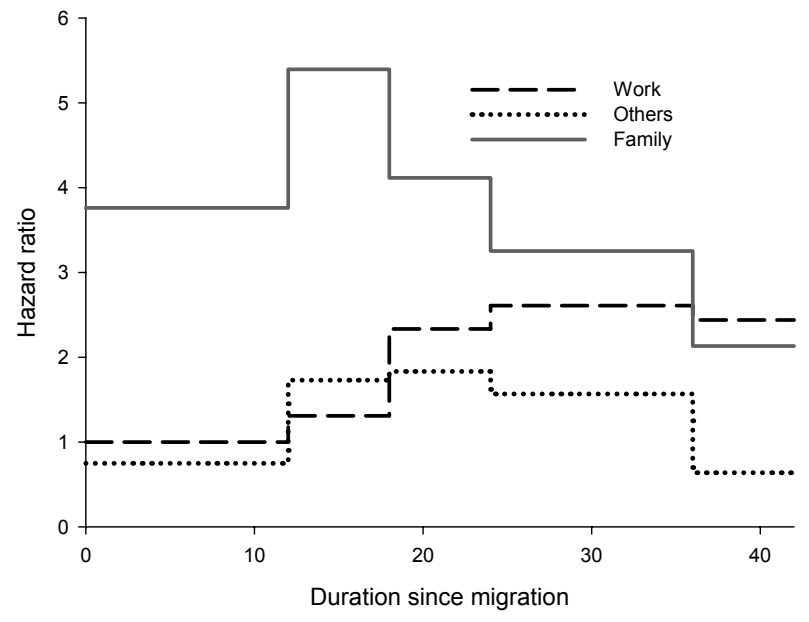

Source: Record linkage from 2003 cohort of immigrants and RHD (authors' calculations).

The last step is to see if the effect of the migratory model is the same for the three communities (Figure 5). The combination of reason for residence permit and citizenship shows a strong heterogeneity among the women. It is clear that, for all women, the risk of having a child is high if they come to Italy for family reasons, but it is also interesting to see that for Romanians who came for family reasons, the risk is lower compared to Albanians and Moroccans; furthermore, that for Moroccans and Albanians there are no significant differences if they come for work reasons. 


\section{Figure 5: Combination of hazard ratio of having a birth after arrival in Italy relative to citizenship and reason for residence permit (Model 3c)}

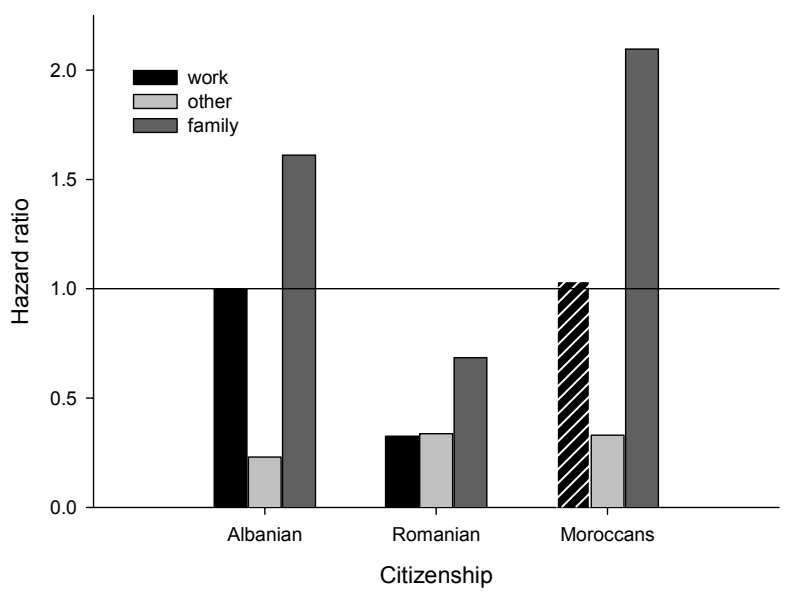

Note: The bar with stripes is not significant. The other covariates of Model 4 are shown in Appendix Table A2 Source: Record linkage from 2003 cohort of immigrants and RHD (authors' calculations).

\section{Discussion}

From the Italian overview at the macro level (e.g., ISTAT 2007) and from the individual results reported, this work confirms that the factor that mainly influences and explains the strong heterogeneity in the reproductive behavior of foreign women is the background of origin (Schoorl 1990; Alders 2000; Andersson 2004; Sobotka 2008). Different citizenships also have different timings of reproduction when the migratory model is taken into account, and this confirms the strong impact of citizenship in the decision to be a mother. At the same time, there is a clear pattern in the timing of motherhood for the type of migration, approximated by reason for residence permits. The high risk for family reasons in the short period is obviously related to the hypothesis of interrelated events, whereas women who come for work reasons need more time to adjust and to decide to have children in the host country. The high risk in the short period for the Moroccans can be understood as an arrival effect but we cannot interpret the slow decrease afterward as an adaptive behavior because of the short period of observation. Milewski (2007) underlined that "Migration, marriage, and a first pregnancy follow in short sequence. This effect would even be more pronounced if we included women of the first immigrant generation that had become pregnant shortly 
before migration, probably in anticipation of the move" (p. 884). Similar results were found in Kyrgyzstan. If migration was related to labor reasons, it slightly reduced the propensity to become a parent, whereas if the migration was motivated by marriage, it also increased first-birth risks, explaining the elevated childbearing propensities of migrants in the short period (Nedoluzhko and Andersson 2007). However, we can expect that women may also have a child after migration to fill the time during the adjustment period when the employment career is disrupted and social networks broken (Bledsoe 2004; Kulu and Milewski 2007) or to secure their marriage in the country of destination by enlarging the family. Another factor for high fertility of marriagemigrants may be their higher stability in the territory, due to the longer presence of their partner in Italy.

In this study, besides the strong arrival effect for the new cohort of immigrants on the risk of having a birth in Italy, we can also identify a strong interrelation between the migration and family behavior (reunification, union, and fertility). This is also confirmed for women who are already married when they migrate. The propensity to have a first child in the host country decreases with the increase of age at arrival, and this is linked with biological factors.

These results help to understand why the trend of TFR of foreign women is slowly declining. In fact, recent immigrants are increasingly coming from lower-fertility countries, especially from Eastern and South-Eastern Europe. One objective of this work was to confirm the strong impact of citizenship and to see how in the short term the differences are more evident. Developments such as these would facilitate population forecasts or local planning concerns such as programming access to kindergarten, especially considering that the composition and the presence of foreigners in Italy is extremely heterogeneous. We therefore encourage policymakers to direct their attention to the various differences in the composition by citizenship of the foreign population present in Italy that we have addressed in this paper.

\section{Acknowledgments}

This work was possible thanks to the internship of Eleonora Mussino at the National Institute of Statistics (ISTAT) on "Register-based Research on Fertility of Foreign Women Using Record Linkage Procedure" for her PhD. We gratefully acknowledge the considerable assistance received from members of ISTAT during these months, in particular from Claudia Iaccarino, Sergio Carfagna, Tiziana Tuoto, and Domenico Gabrielli. We would like to express our appreciation to Dr. Sabrina Prati for the excellence of her supervision. We are also very grateful to three anonymous referees who through their valuable suggestions have enabled us to greatly improve the article. 


\section{References}

Alders, M. (2000). Cohort fertility of migrant women in the Netherlands. Paper presented at the BSPS-NVD-URU Conference, Utrecht, the Netherlands, August 31- September 1, 2000.

Allison, P.D. (1984). Event history analysis: Regression for longitudinal event data. Newbury Park: Sage.

Andersson, G. (2004). Childbearing after migration: Fertility patterns of foreign-born women in Sweden. International Migration Review 38(2): 747-774. doi:10.1111/ j.1747-7379.2004.tb00216.x.

Baizan, P., Aassve, A., and Billari, F.C. (2003). Cohabitation, marriage, and first birth: The interrelationship of family formation events in Spain. European Journal of Population 19(2): 147-169. doi:10.1023/A:1023343001627.

Bean, F.D. and Tienda, M. (1990). The Hispanic population of the United States. In: National Committee for Research on the 1980 Census (ed.). The Population of the United States in the 1980s. New York: Russell Sage Foundation.

Bean, F.D. and Wood, C.H. (1974). Ethnic variation in the relationship between income and fertility. Demography 11(4): 629-640. doi:10.2307/2060474.

Billari, F.C. (2008). Lowest-low fertility in Europe: Exploring the causes and finding some surprises. Japanese Journal of Population 6(1): 2-18.

Blangiardo, G.C. (2009). Immigrazione straniera e fecondità: Un rapporto in evoluzione. Firenze: Neodemos.

Blau, F.D. (1992). The fertility of immigrant women: Evidence from high-fertility source countries. In: George, J.B. and Freeman, R.B. (eds.). Immigration and the Work Force: Economic Consequences for the United States and Source Areas. Chicago and London: The University of Chicago Press: 93-133.

Bledsoe, C.H. (2004). Reproduction at the margins: Migration and legitimacy in the New Europe. Demographic Research SC3(4): 87-116. doi:10.4054/ DemRes.2004.S3.4.

Bledsoe, C.H., Houle, R., and Sow, P. (2007). High fertility Gambians in low fertility Spain: The dynamics of child accumulation across transnational space. Demographic Research 16(12): 375-412. doi:10.4054/DemRes.2007.16.12. 
Blossfeld, H.-P. and Rohwer, G. (2002). Techniques of event history modeling: New approaches to causal analysis. Mahwah: Lawrence Erlbaum Associates, Inc. Publishers.

Brockerhoff, M. (1995). Fertility and family planning in African cities: The impact of female migration. Journal of Biosocial Science 27(3): 347-358. doi:10.1017/ S0021932000022872.

Caltabiano, M. (2006). Recenti sviluppi della fecondità per coorti in Italia. Department of Statistical Sciences, University of Padova (Working Paper Series 2/06).

Coleman, D.A. (1994). Trends in fertility and intermarriage among immigrant populations in Western Europe as measures of integration. Journal of Biosocial Science 26(1): 107-136. doi:10.1017/S0021932000021106.

Courgeau, D. (1989). Family formation and urbanization. Population: An English Selection 44(1): 123-146.

Courgeau, D. and Lelievre, E. (2006). Motivations for Migration. In: Caselli, G., Vallin, J., and Wunsch, G. (eds.). Demography: Analysis and synthesis. Burligton, San Diego, and London: Elsevier.

de Filippo, E. and Strozza, S. (2011). Le migrazioni interne degli stranieri in Italia. Sociologia del lavoro 121: 168-195.

De Santis, G. (2010). Mobilità a corto e lungo raggio e pendolarismo della popolazione Italiana. In: Livi Bacci, M. (ed.). Demografia del capitale umano. Bologna: Il Mulino: 123-138.

Delgado Perez, M. and Livi Bacci, M. (1992). Fertility in Italy and Spain: The lowest in the world. Family Planning 24(4): 162-167+171.

Fellegi, I.P. and Sunter, A.B. (1969). A theory for record linkage. Journal of the American Statistical Association 64(328): 1183-1210. doi:10.2307/2286061.

Ferrara, R., Giorgi, P., Mamolo, M., and Strozza, S. (2009). Fertility in Italy and Spain: What is the role played by foreigners? A decomposition model results. Paper presented at the XXVI IUSSP International Population Conference. Marrakech, September 27 - October 2, 2009.

Fleischer, A. (2008). Marriage over space and time among male migrants from Cameroon to Germany. Beyond national boundaries: Migration and transnationality in Europe. Rostock: Max-Planck-Institute for Demographic Research (MPIDR working paper WP 2008-006). 
Ford, K. (1990). Duration of residence in the United States and the fertility of U.S. immigrants. International Migration Review 24(1): 34-68. doi:10.2307/2546671.

Goldstein, J.R., Sobotka, T., and Jasilioniene, A. (2009). The end of "lowest-low" fertility? Population and Development Review 35(4): 663-699. doi:10.1111/ j.1728-4457.2009.00304.x.

Goldstein, S. and Goldstein, A. (1981). The impact of migration on fertility: An 'own children' analysis for Thailand. Population Studies 35(2): 265-284. doi:10.1080/ 00324728.1981 .10404967$.

Hervitz, H.M. (1985). Selectivity, adaptation, or disruption? A comparison of alternative hypotheses on the effects of migration on fertility: The case of Brazil. International Migration Review 19(2): 293-317. doi:10.2307/2545774.

ISTAT (2007). La popolazione straniera residente in Italia al $1^{\circ}$ gennaio 2007. Roma: ISTAT Statistiche in Breve.

ISTAT (2010). Natalità e fecondità della popolazione residente: Caratteristiche e tendenze recenti 2008. Roma: ISTAT Statistiche in Breve.

Kahn, J.R. (1988). Immigrant selectivity and fertility adaptation in the United States. Social Forces 67(1): 108-128. doi:10.2307/2579102.

Kahn, J.R. (1994). Immigrant and native fertility during the 1980s: Adaptation and expectation for the future. International Migration Review 28(3): 501-519. doi: $10.2307 / 2546818$.

Kennedy, R.E. (1973). Minority group status and fertility: The Irish. American Journal of Sociology 38(1): 85-96. doi:10.2307/2094333.

Kulu, H. and Milewski, N. (2007). Family change and migration in the life course: An introduction. Demographic Research 17(19): 567-590. doi:10.4054/ DemRes.2007.17.19.

Lindstrom, D.P. and Giorguli Saucedo, S. (2007). The interrelationship of fertility, family maintenance and Mexico-U.S. migration. Demographic Research 17(28): 821-858. doi:10.4054/DemRes.2007.17.28.

Mayer, J. and Riphahn, R.T. (2000). Fertility assimilation of immigrants: Evidence from count data models. Journal of Population Economics 13(2): 241-261. doi:10.1007/s001480050136. 
Milewski, N. (2007). First child of immigrant workers and their descendants in West Germany: Interrelation of events, disruption, or adaptation? Demographic Research 17(29): 859-896. doi:10.4054/DemRes.2007.17.29.

Milewski, N. (2010). Fertility of immigrants: A two-generational approach in Germany. Heidelberg, Dordrecht, London, and New York: Springer.

Mulder, C.H. and Wagner, M. (1993). Migration and marriage in the life course: A method for studying synchronized events. European Journal of Population 9(1): 55-76. doi:10.1007/BF01267901.

Mussino, E., Iaccarino, C., Prati, S., and Strozza, S. (2009). Short-term reproductive behaviour of foreign women who became mothers between 2002-2006 in Italy. Vienna Yearbook of Population Research 2009: 63-82. doi:10.1553/ populationyearbook2009s63.

Mussino, E. and Van Raalte, A. (2008). Fertility of migrant women: A comparative study between Italy and Russia. Rostock: Max Planck Institute for Demographic Research (MPIDR Working Paper WP 2008-026).

Nedoluzhko, L. and Andersson, G. (2007). Migration and first-time parenthood: Evidence from Kyrgyzstan. Demographic Research 17(25): 741-774. doi:10.4054/DemRes.2007.17.25.

Ng, E. and Nault, F. (1997). Fertility among recent immigrant women to Canada, 1991: An examination of the disruption hypothesis. International Migration Review 35(4): 559-580. doi:10.1111/1468-2435.00027.

Ribe, H. and Schultz, T.P. (1980). Migrant and native fertility in Colombia in 1973: Are migrants selected according to their reproductive preferences. New Haven: Yale University, Economic Growth Center.

Rinesi, F. (2009). Fecondità attesa e realizzata delle madri italiane. [Phd Thesis]. Roma: Sapienza Università di Roma. Dipartimento di Studi Economici, Sociali, Attuariali e Demografici.

Ritchey, P.N. (1975). The effects of minority group status on fertility: A re-examination of concepts. Population Studies 29(2): 249-257. doi:10.2307/2173510.

Schoenmaeckers, R.C., Lodewijckx, E., and Gadeyne, S. (1999). Marriages and fertility among Turkish and Moroccan women in Belgium: Results from census data. International Migration Review 33(4): 901-928. doi:10.2307/2547357. 
Schoorl, J.J. (1990). Fertility adaptation of Turkish and Moroccan women in the Netherlands. International Migration 28(4): 477-495. doi:10.1111/j.14682435.1990.tb00493.x.

Singley, S.G. and Landale, N.S. (1998). Incorporating origin and process in migration fertility frameworks: The case of Puerto Rican women. Social Forces 76(4): 1437-1464. doi:10.2307/3005841.

Sly, D.F. (1970). Minority Group status and fertility: An extension of Goldscheider and Uhlenberg. American Journal of Sociology 76(3): 443-459. doi:10.1086/224951.

Sobotka, T. (2008). Overview chapter 7: The rising importance of migrants for childbearing in Europe. Demographic Research 19(9): 225-248. doi:10.4054/ DemRes.2008.19.9.

Spinelli, E. (2005). Immigrazione e servizio sociale. Roma: Carocci.

Stephen, E.H. and Bean, F.D. (1992). Assimilation, disruption, and the fertility of Mexican American women in the United States. International Migration Review 26(1): 67-88. doi:10.2307/2546937.

Terzera, L. (2006). Famiglia e fecondità. In: Paterno, A., Strozza, S., and Terzera, L. (eds.). Sospesi tra due rive: Migrazioni e insediamenti di marocchini e albanesi. Milano: Franco Angeli.

Toulemon, L. (2004). Fertility among immigrant women: New data, a new approach. Population and Societies 400.

Toulemon, L. and Mazuy, M. (2004). Comment prendre en compte l'âge à l'arrivée et le durée de séjour en France dans la mesure de la fécondité des immigrants? Documents de travail Paris. INED.

Wagner, M. (1990). Education and migration. In: Mayer, K.U. and Tuma, N.B. (eds.). Event history analysis in life course research. Madison: The University of Wisconsin Press: 129-145.

Willekens, F. (1991). Understanding the interdependence between parallel careers. In: Siegers, J.J., Dejong-Gierveld, J., and Van Imhoff, E. (eds.). Female Labour Market Behaviour and Fertility: A Rational-Choice Approach. Berlin: Springer: 11-31. 


\section{Appendix}

Table A1: Risk of first birth $(\mathrm{N}=\mathbf{2 3 , 9 2 3})$ - Distribution of time at risk and of observed Events (variables in final model)

\begin{tabular}{|c|c|c|c|}
\hline & $\begin{array}{c}\text { Person-Time } \\
\text { (in Months) }\end{array}$ & $\begin{array}{l}\text { Percentage of } \\
\text { Person-Time }\end{array}$ & $\begin{array}{c}\text { Number of } \\
\text { observed Events }\end{array}$ \\
\hline \multicolumn{4}{|l|}{ Duration: } \\
\hline$<=12$ & 279468 & 32.8 & 2295 \\
\hline 12_18 & 126245 & 14.8 & 1273 \\
\hline $18-24$ & 119768 & 14.0 & 880 \\
\hline $24-36$ & 226730 & 26.6 & 1242 \\
\hline$>36$ & 100612 & 11.8 & 385 \\
\hline \multicolumn{4}{|l|}{ Citizenship: } \\
\hline Romanian & 263554 & 30.9 & 980 \\
\hline Albanian & 414864 & 48.7 & 2545 \\
\hline Moroccan & 174405 & 20.5 & 2550 \\
\hline \multicolumn{4}{|c|}{ Reason for residence permit: } \\
\hline Work & 164206 & 19.3 & 274 \\
\hline Other & 183492 & 21.5 & 206 \\
\hline Family & 505125 & 59.2 & 5595 \\
\hline \multicolumn{4}{|l|}{ Age at first entry: } \\
\hline$<20$ & 169314 & 19.9 & 1443 \\
\hline $20-24$ & 194191 & 22.8 & 2359 \\
\hline $25-29$ & 170111 & 20.0 & 1432 \\
\hline $30-34$ & 122429 & 14.4 & 611 \\
\hline 35 and older & 196778 & 23.1 & 230 \\
\hline \multicolumn{4}{|c|}{ Deadline for permit: } \\
\hline Determinate & 828534 & 97.2 & 5616 \\
\hline Indeterminate & 24289 & 2.9 & 459 \\
\hline \multicolumn{4}{|l|}{ Marital status: } \\
\hline Other & 327115 & 38.4 & 564 \\
\hline Married & 525708 & 61.6 & 5511 \\
\hline \multicolumn{4}{|c|}{ Italian geographical division: } \\
\hline North-West & 277528 & 32.5 & 2393 \\
\hline North-East & 259734 & 30.5 & 1935 \\
\hline Central & 208376 & 24.4 & 1184 \\
\hline South \& Islands & 107185 & 12.6 & 563 \\
\hline Total & 852823 & 100.0 & 6075 \\
\hline
\end{tabular}


Table A2: Risk of having first birth: Other variables

\begin{tabular}{|c|c|c|c|}
\hline & Model 3a & Model 3b & Model 3c \\
\hline \multicolumn{4}{|l|}{ Duration: } \\
\hline$<=12$ & & & 1 \\
\hline $12-18$ & & & $1.44^{* * *}$ \\
\hline $18-24$ & & & $1.15^{\star \star *}$ \\
\hline $24-36$ & & & $0.94^{*}$ \\
\hline$>36$ & & & $0.63^{\star \star \star}$ \\
\hline \multicolumn{4}{|l|}{ Citizenship: } \\
\hline Romanians & & $0.45^{* * *}$ & \\
\hline Albanians & & 1 & \\
\hline Moroccans & & $1.31^{* * *}$ & \\
\hline \multicolumn{4}{|c|}{ Reason for residence permit: } \\
\hline Work & 1 & & \\
\hline Other & $0.69^{* * *}$ & & \\
\hline Family & $1.99^{\star * \star}$ & & \\
\hline \multicolumn{4}{|l|}{ Age at first entry: } \\
\hline$<20$ & 1 & 1 & 1 \\
\hline $20-24$ & $1.10^{* *}$ & $1.10^{* *}$ & $1.09^{*}$ \\
\hline $25-29$ & $0.79^{* * *}$ & $0.78^{* * *}$ & $0.77^{* * *}$ \\
\hline $30-34$ & $0.42^{* * *}$ & $0.42^{\star * *}$ & $0.42^{\star \star *}$ \\
\hline 35 and older & $0.09^{* * *}$ & $0.09^{* * *}$ & $0.09^{* * *}$ \\
\hline \multicolumn{4}{|c|}{ Deadline for permit: } \\
\hline Determinate & 1 & 1 & 1 \\
\hline Indeterminate & $1.24^{* * *}$ & $1.24^{* * *}$ & $1.24^{* * *}$ \\
\hline \multicolumn{4}{|l|}{ Marital Status: } \\
\hline Other & 1 & 1 & 1 \\
\hline Married & $3.94^{* * *}$ & $3.96^{* * *}$ & $3.79^{* \star *}$ \\
\hline \multicolumn{4}{|c|}{ Italian geographical division: } \\
\hline North-West & 1 & 1 & 1 \\
\hline North-East & 0.96 & 0.96 & 0.96 \\
\hline Central & $0.90^{* *}$ & $0.90^{* *}$ & $0.90^{* *}$ \\
\hline South \& Islands & $0.83^{* * *}$ & $0.83^{* * *}$ & $0.82^{\star \star *}$ \\
\hline$\overline{\mathrm{LL}}$ & -15417.08 & -15416.73 & -15439.20 \\
\hline $\mathrm{BIC}$ & 31134.41 & 31133.72 & 31132.47 \\
\hline AIC & 30886.15 & 30885.46 & 30922.40 \\
\hline
\end{tabular}

${ }^{*}<0.05^{* *}<0.01^{* * *}<0.001$ 